\title{
An elementary finite element exercise to stimulate computational thinking in engineering education
}

\author{
Majid Aleyaasin (1)
}

Fraser Noble Building, School of Engineering, University of Aberdeen, Aberdeen, UK

\section{Correspondence}

Majid Aleyaasin, Fraser Noble Building, School of Engineering, University of Aberdeen, Aberdeen AB24 3UE, UK.

Email: eng780@abdn.ac.uk

\begin{abstract}
In this paper, an elementary exercise that can strengthen computational thinking in engineering analysis and design is outlined and discussed. The exercise is a simple finite element assignment designed for the M.Sc. students in Mechanical and Civil Engineering. It comprises a two-member frame with a variety of loading that can be solved manually without using any computer programming. Individual data is allocated to each student, and they have been asked to report their results like reaction forces, reaction moments and stresses. Thereafter they have modelled the same frame structure in commercially available finite element method (FEM) software ABAQUS, from which a substantial output file is created for such a simple problem. In the final stage, each student highlights the ABAQUS results that can be compared and commented upon with the results obtained from their manual calculations. Since the assignment is individual, it provides a justifiable connection between computational thinking of an individual mind, with printed outputs of a complicated FEM software. Implementing this assignment in M.Sc. finite element course at Aberdeen University has been very successful. This enabled individual students to relate their computational thinking, with the results of complicated FEM software in engineering. It is concluded that such exercises can stimulate computational thinking in engineering education. Moreover, they can be used in other engineering fields where FEM is applicable, either at the university level or Professional and Career Development courses in engineering.
\end{abstract}

\section{K E Y W O R D S}

computational thinking, engineering education, finite element, STEM

\section{1 | INTRODUCTION}

Science, Technology, Engineering, and Mathematics (STEM) education is an important issue in the 21st century. The aim is to strengthen the self-efficacy of future employees in this highly competitive industrial age. Harvesting computational thinking in teenagers' minds is the starting point for this goal, whereby robotic and computer games may be used [13].

Recently, maker activities have been arranged by a variety of tools like electric circuits, E-textiles, Makey Makey, Circuits on Breadboards, and Arduinos in 
which the end goal is STEM learning in engineering and physics [21]. Then the outcomes of those can be integrated with computational thinking (CT).

A variety of methods are under investigation to integrate CT with STEM. Recently, some of those activities are reported in [12] in the field of K-12 education. Moreover, teachers also should be trained for fostering CT in K-12 educators, and the mechanisms of their training are explained in [10].

It is obvious that $\mathrm{CT}$ is a fundamental skill that some graduate students should learn. This is necessary when graduates choose a career in engineering and computer-based industries. To learn this in advance, CT skills in middle school ages, are implemented in some schools by using agile software [8]. This method of CT teaching has been recognised as an effective tool for training future software engineers [7].

Recently, new effective techniques using Gamification [18] and Scratch and App [19] tools are also developed to improve computational and programming skills in secondary education.

It is well understood that computational thinking acquisition (CTA) is a necessary prelude for end user developer (EUD) that can be grown to end user programmer (EUP) [16].

\section{1 | CT in engineering education}

It is obvious that $\mathrm{CT}$ skills cannot be limited to $\mathrm{K}-12$ education only. It is proved that in Undergraduate (UG) and Postgraduate (PG) university education, refreshing and fostering CT skills in students is vitally necessary [9]. The students will be targeted for CT skills, in modelling and simulation practices, which they do in UG and PG engineering courses [15]. This refreshes their knowledge in $\mathrm{CT}$ before their employment.

An important topic for engineering students in UG or PG studies is finite element analysis (FEA). This course helps them in the analysis and design of machines and structures. They continue using FEA later, in many industries during their career, via sophisticated and commercially available software like ABAQUS [6]. To interpret the substantial outputs of such programs, they need to have prefostered CT skills to understand the computational mechanics behind the software.

To prefoster the above CT skills, substantial effort has been made by publishing a variety of finite element method (FEM) books for different branches of engineering. Only a few books discuss the relationship between modern FEM software and the underlying theories in computational mechanics [11]. The author herein believes that CT skills can be improved significantly if students do particular FEA assignments in civil and mechanical engineering degrees. Many individual assignments have been practiced previously in other courses [2] and resulted in successful outcomes. Can we extend the practice to include CT skills?

The research question in this article has been, "How a particular FEA exercise for engineering students can include the elements of computational thinking?" This article describes the elements of computational thinking of such exercises. To prove it, the intrinsic details of the assignment are examined. It is shown that the exercise in this article is closely tied with computational thinking.

\section{2 | BACKGROUND AND CONTRIBUTION}

In this article, a particular FEA assignment is designed and allocated to M.Sc. students. It is shown that by doing the assignment, students' CT skills will be improved. The assignment is about a simple frame structure. Each student received different dimensions of that structure in a PG finite element course. First they have to implement their CT skills to construct the overall stiffness matrix, and calculate the reaction forces, moments, displacements, and stresses. In the next step, they have to model that structure on a well-known FEM software ABAQUS [6]. Thereafter, they have to extract some results from the output files, to compare them with their manual calculations.

The importance of FEM in engineering education is the main reason to promote CT by such exercise. Any FEM exercise intrinsically is a $\mathrm{CT}$ problem because it can be programmed in a way to be solved computers. Further connections between FEM and CT are discussed in [5]. A particular feature of the exercise is that it can be done by both ABAQUS (commercial software) and also by CT steps used by individual students. Upon completion of the exercise, students have a tool (ABAQUS) to verify their results. It can check if the CT steps they have used in this exercise have been implemented correctly and successfully.

A group of 12 distance-learning students with another group of 8 on-campus students participated in a FEM exercise that is described in the next section. Each student provided a calculation code for the solution of a simple structure. The algorithm of that code includes all steps of computational thinking. To test the successfulness of the practice, they have compared their results with the outputs of FEM commercial software for the same simple structure. It is shown that students can evaluate their CT skills and 


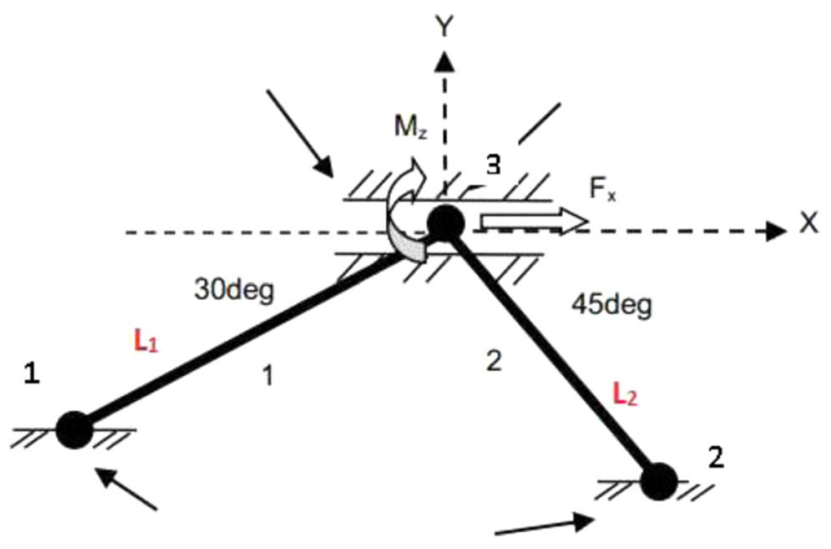

FIGURE 1 A frame with two elements

strengthen them by successive trials, which are explained in the following sections.

\section{3 | COMPUTATIONAL STEPS FOR ANALYSIS OF A SIMPLE FRAME}

In Figure 1, a simple frame is shown with two elements No. 1 with nodes numbers 1 and 3 and length $L_{1}$ and No. 2 with nodes numbers 2 and 3 and length $L_{2}$. The angles $\theta_{1}=30^{\circ}$ and $\theta_{2}=45^{\circ}$ are the orientations of the elements with horizontal axis $X$.

For each element there exist a transformation matrix that converts the local to the global coordinate, with the following detail [14]:

$$
\mathbf{T}_{i}=\left[\begin{array}{cccccc}
\cos \theta_{i} & \sin \theta_{i} & 0 & 0 & 0 & 0 \\
-\sin \theta_{i} & \cos \theta_{i} & 0 & 0 & 0 & 0 \\
0 & 0 & 1 & 0 & 0 & 0 \\
0 & 0 & 0 & \cos \theta_{i} & \sin \theta_{i} & 0 \\
0 & 0 & 0 & -\sin \theta_{i} & \cos \theta_{i} & 0 \\
0 & 0 & 0 & 0 & 0 & 1
\end{array} \mid i=1,2\right.
$$

Each element has a connectivity matrix by which we can assemble the individual stiffness matrices in global coordinate; these matrices are:

$$
\begin{aligned}
& \mathbf{a}_{\mathbf{E} 1}=\left[\begin{array}{lllllllll}
1 & 0 & 0 & 0 & 0 & 0 & 0 & 0 & 0 \\
0 & 1 & 0 & 0 & 0 & 0 & 0 & 0 & 0 \\
0 & 0 & 1 & 0 & 0 & 0 & 0 & 0 & 0 \\
0 & 0 & 0 & 0 & 0 & 0 & 1 & 0 & 0
\end{array} \mid\right. \\
& \mathbf{a}_{\mathrm{E} 2}=\left[\begin{array}{lllllllll}
0 & 0 & 0 & 1 & 0 & 0 & 0 & 0 & 0 \\
0 & 0 & 0 & 0 & 1 & 0 & 0 & 0 & 0 \\
0 & 0 & 0 & 0 & 0 & 1 & 0 & 0 & 0 \\
0 & 0 & 0 & 0 & 0 & 0 & 1 & 0 & 0
\end{array} \mid\right. \\
& \left.\mid \begin{array}{lllllllll}
0 & 0 & 0 & 0 & 0 & 0 & 0 & 1 & 0 \\
0 & 0 & 0 & 0 & 0 & 0 & 0 & 0 & 1
\end{array}\right\rfloor
\end{aligned}
$$

For each element there is a local stiffness given by this [1]:

$$
\mathbf{K}_{\mathbf{E i}}=\left[\begin{array}{cccccc|l}
\frac{E A_{i}}{L_{i}} & 0 & 0 & -\frac{E A_{i}}{L_{i}} & 0 & 0 & \vdots \\
0 & \frac{12 E I_{i}}{\left(1+\phi_{i} L_{i}^{3}\right.} & \frac{6 E I_{i}}{\left(1+\phi_{i}\right) L_{i}^{2}} & 0 & -\frac{12 E I_{i}}{\left(1+\phi_{i}\right) L_{i}^{3}} & \frac{6 E I_{i}}{\left(1+\phi_{i}\right) L_{i}^{2}} & \vdots \\
0 & \frac{6 E I_{i}}{\left(1+\phi_{i}\right) L_{i}^{2}} & \frac{\left(4+\phi_{i}\right) E I_{i}}{\left(1+\phi_{i}\right) L_{i}} & 0 & -\frac{6 E I_{i}}{\left(1+\phi_{i}\right) L_{i}^{2}} & \frac{\left(2-\phi_{i} E I_{i}\right.}{\left(1+\phi_{i}\right) L_{i}} & \mid \\
-\frac{E A_{i}}{L_{i}} & 0 & 0 & \frac{E A_{i}}{L_{i}} & 0 & 0 & 0 \\
0 & -\frac{12 E I_{i}}{\left(1+\phi_{i}\right) L_{i}^{3}} & -\frac{6 E I_{i}}{\left(1+\phi_{i} L_{i}^{2}\right.} & 0 & \frac{12 E I_{i}}{\left(1+\phi_{i} L_{i}^{3}\right.} & -\frac{6 E I_{i}}{\left(1+\phi_{i} L_{i}^{2}\right.} & \mid \\
0 & \frac{6 E I_{i}}{\left(1+\phi_{i}\right) L_{i}^{2}} & \frac{\left(2-\phi_{i}\right) E I_{i}}{\left(1+\phi_{i}\right) L_{i}} & 0 & -\frac{6 E I_{i}}{\left(1+\phi_{i}\right) L_{i}^{2}} & \frac{\left(4+\phi_{i}\right) E I_{i}}{\left(1+\phi_{i}\right) L_{i}}
\end{array}\right]
$$

In the above matrix $E$ is the modulus of elasticity, $L_{i}$ is the length, $I_{i}$ is the second moment of beam cross section. For a pipe cross section, we have:

$$
\begin{aligned}
& I_{i}=\frac{\pi}{64}\left(D_{i}^{4}-\left(D_{i}-2 t_{i}\right)^{4}\right) \\
& A_{i}=\frac{\pi}{4}\left(D_{i}^{2}-\left(D_{i}-2 t_{i}\right)^{2}\right) \quad i=1,2
\end{aligned}
$$

In which $D_{i}$ is the outer diameter and $t_{i}$ is the thickness of the pipe. The parameter $\phi_{i}$ is:

$$
\phi_{i}=\frac{12 E I_{i}}{G A_{i} L_{i}^{2}}
$$

In (5), the $G$ is shear modulus and is given in terms of Poisson ratio $\nu$ by:

$$
G=\frac{E}{2(1+v)}
$$

The global stiffness matrix of each element is [11]:

$$
\mathbf{K}_{\mathrm{Ei}}^{*}=\mathbf{T}_{\mathbf{i}}^{\mathbf{T}} \mathbf{K}_{\mathrm{Ei}} \mathbf{T}_{\mathbf{i}} \quad i=1,2
$$

The overall global stiffness matrix for this frame is [5]:

$$
\mathbf{K}_{\mathrm{G}}=\mathbf{a}_{\mathrm{E} 1}^{\mathbf{T}} \mathbf{K}_{\mathrm{E} 1}^{*} \mathbf{a}_{\mathrm{E} 1}+\mathbf{a}_{\mathrm{E} 2}^{\mathbf{T}} \mathbf{K}_{\mathrm{E} 2}^{*} \mathbf{a}_{\mathrm{E} 2}
$$

This simple frame has three nodes only, and each node in the plane beam has 3 Degrees Of Freedom (DOF), that is, linear displacements $u_{i}$ and $v_{i}$ and rotation $\varphi_{i}$. According to Figure 1, the two elements are welded at node 3. Further 7 DOF's are fixed denoted by $\mathbf{r}_{\mathbf{e}}$ and defined by:

$$
\mathbf{r}_{\mathbf{e}}=\left[\begin{array}{lllllll}
u_{1} & v_{1} & \varphi_{1} & u_{2} & v_{2} & \varphi_{2} & v_{3}
\end{array}\right]^{\mathbf{T}}
$$

The remaining DOFs are not fixed, noted by $\mathbf{r}_{\mathbf{f}}$ and defined by:

$$
\mathbf{r}_{\mathbf{f}}=\left[\begin{array}{ll}
u_{3} & \varphi_{3}
\end{array}\right]^{\mathbf{T}}
$$

Based on constrained and unconstrained DOFs, the global stiffness matrix $\mathbf{K}_{\mathbf{G}}$ can be partitioned into four parts as follows: 


$$
\begin{aligned}
& \begin{array}{llllllll}
K_{G 11} & K_{G 12} & K_{G 13} & K_{G 14} & K_{G 15} & K_{G 16} & K_{G 18}
\end{array} \\
& \mathbf{K}_{\mathbf{e e}}=\left|\begin{array}{lllllll}
K_{G 21} & K_{G 22} & K_{G 23} & K_{G 24} & K_{G 25} & K_{G 26} & K_{G 28} \\
K_{G 31} & K_{G 32} & K_{G 33} & K_{G 34} & K_{G 35} & K_{G 36} & K_{G 38} \\
K_{G 41} & K_{G 42} & K_{G 43} & K_{G 44} & K_{G 45} & K_{G 46} & K_{G 48} \\
K_{G 51} & K_{G 52} & K_{G 53} & K_{G 54} & K_{G 55} & K_{G 56} & K_{G 58} \\
K_{G 61} & K_{G 62} & K_{G 63} & K_{G 64} & K_{G 65} & K_{G 66} & K_{G 68}
\end{array}\right| \\
& \left\lceil\begin{array}{ll}
K_{G 17} & K_{G 19}
\end{array}\right. \\
& \mathbf{K}_{\text {ef }}=\left|\begin{array}{ll}
K_{G 27} & K_{G 29} \\
K_{G 37} & K_{G 39} \\
K_{G 47} & K_{G 49} \\
K_{G 57} & K_{G 59} \\
K_{G 67} & K_{G 69}
\end{array}\right| \\
& \mathbf{K}_{\mathbf{f e}}=\left[\begin{array}{lllllll}
K_{G 71} & K_{G 72} & K_{G 73} & K_{G 74} & K_{G 75} & K_{G 76} & K_{G 78} \\
K_{G 91} & K_{G 92} & K_{G 93} & K_{G 94} & K_{G 95} & K_{G 96} & K_{G 98}
\end{array}\right] \\
& \mathbf{K}_{\mathbf{f f}}=\left[\begin{array}{ll}
K_{G 77} & K_{G 79} \\
K_{G 97} & K_{G 99}
\end{array}\right]
\end{aligned}
$$

The external force-moment vector $\mathbf{R}_{\mathbf{f}}$ applied to the frame is applied to node 3 (see Figure 1) and is given to all student like this:

$$
\mathbf{R}_{\mathbf{f}}=\left[\begin{array}{l}
R_{7} \\
R_{9}
\end{array}\right]=\left[\begin{array}{l}
F_{3 x} \\
M_{3 z}
\end{array}\right]=\left[\begin{array}{c}
1 \mathrm{MN} \\
-2.4 \mathrm{MNm}
\end{array}\right]
$$

Further common data given to the students are $D_{1}=800 \mathrm{~mm}$ and $t_{1}=20 \mathrm{~mm}$ for the first element, $D_{2}=600 \mathrm{~mm}$ and $t_{2}=15 \mathrm{~mm}$ for the second element, together with numerical values like $E=200 \mathrm{GPa}$ and $v=0.3$. However, different lengths $L_{1}$ and $L_{2}$ are given to students according to the following table to report different results.

Then they have been asked to use sequence of formulas from (1) to (11) to find the resulted linear and angular displacements (in node 3) via this formula by considering $\mathbf{r}_{\mathbf{e}}=0$ in (9):

$$
\mathbf{r}_{\mathbf{f}}=\left[\begin{array}{l}
u_{3} \\
\varphi_{3}
\end{array}\right]=\mathbf{K}_{\mathbf{f f}}^{-1}\left(\mathbf{R}_{\mathbf{f}}-\mathbf{K}_{\mathbf{f e}} \mathbf{r}_{\mathbf{e}}\right)
$$

Moreover, they report reaction forces $\mathrm{R}_{\mathrm{e}}$ forces considering $\mathbf{r}_{\mathbf{e}}=0$ in (11) from the following formula:

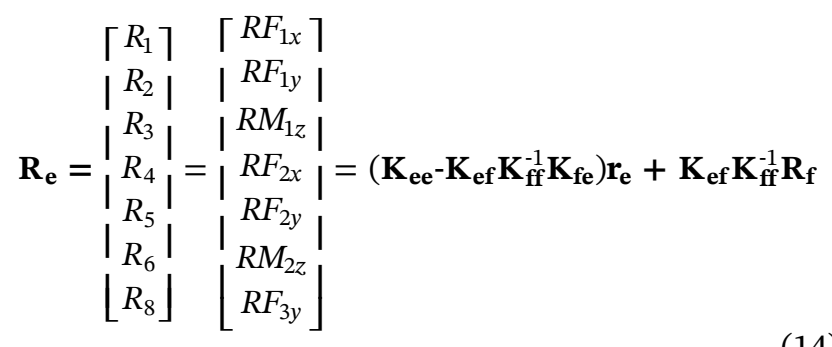

\section{4 | CT STEPS IN THE EXERCISE}

CT is the procedure for formulating a problem and expressing the solution in an approach that can be programmed by computers. It consists of four major steps, which are explained in [3].

\section{1 | Decomposition}

In this step, a large or complex problem (multielement model of a system) can be solved by breaking it down into some smaller problems (single elements) in which the solution for it is much easier. This step is inherently embedded in any FEM exercise, including the one in the previous section.

\section{2 | Pattern recognition}

In this step, the patterns or trends in all small problems (single elements) should be identified. The common features for each element in this exercise are:

The transformation and connectivity matrices for each element shown in Equations (1) and (2).

The constrained and unconstrained DOF expressed by (9) and (10)

The stiffness matrix for each element given by Equations (3)-(6).

\section{3 | Abstraction}

In this step, we identify the similarities and differences between small problems (elements) and work out the solution based on that. In this exercise, the main similarities are transformation and stiffness matrices in (1) and (3). However, the main difference is the connectivity matrix for each element given by (2).

\section{4 | Algorithm design}

It is a procedure by which the step-by-step solution of the problem can be described. In this exercise, the procedure consists of:

Converting the local to the global stiffness matrix for each element via Equation (7). 
Assembling the individual stiffness matrices to find the global stiffness matrix $\mathbf{K}_{\mathbf{G}}$ for the whole system by using Equation (8).

Partitioning the global stiffness matrix into four submatrices $\mathbf{K}_{\mathbf{e e}}, \mathbf{K}_{\mathbf{e f}}, \mathbf{K f e}$, and $\mathbf{K}_{\mathbf{f f}}$ according to (11).

Finding unconstrained displacements from (13) and the reaction forces from (14) by using the above submatrices.

All of the above steps are summarised in Figure 2, in form of a flow chart. In this flow chart, the ABAQUS verification of the CT practice is also included so that a complete picture of the CT practice in the exercise can be demonstrated.

\section{5 | FEM SOFTWARE FOR ANALYSIS OF THE SAME FRAME}

The same frame has been analysed in commercially available FEM software ABAQUS. We have used two beam elements type B22 with pipe cross section, with similar dimension and material properties. To achieve higher accuracy instead of three nodes in the previous part, we have used five nodes. As an example, we have used the data $L_{1}=8 \mathrm{~m}$ and $L_{2}=6 \mathrm{~m}$ from Table 1 . The displacement map of the frame is shown in Figure 3 and is obtained via ABAQUS.

The students have used sequence or formulas (1)-(11) and found the results from (13) and (14). Those results are displayed in the second column of Table 2 below. Moreover, in the third column of Table 2, the corresponding result via ABAQUS are also shown. The comparison shows that differences are negligible, which means that an individual student has successfully done the assignment with accurate CT.

\section{1 | Verification of further practical results}

To reveal further practical results, a deeper analysis is required. To express the transversal and rotational DOF in (9), the following shape functions are defined:

$$
\begin{gathered}
\mathrm{N}_{1 y}=\frac{1}{\mathrm{~L}^{3}}\left(2 \mathrm{x}^{3}-3 \mathrm{x}^{2} \mathrm{~L}+\mathrm{L}^{3}\right) \quad \mathrm{N}_{1 \varphi}=\frac{1}{\mathrm{~L}^{3}}\left(\mathrm{x}^{3}-2 \mathrm{x}^{2} \mathrm{~L}+\mathrm{xL}^{2}\right) \\
\mathrm{N}_{2 \mathrm{y}}=\frac{1}{\mathrm{~L}^{3}}\left(-2 \mathrm{x}^{3}+3 \mathrm{x}^{2} \mathrm{~L}\right) \quad \mathrm{N}_{2 \varphi}=\frac{1}{\mathrm{~L}^{3}}\left(\mathrm{x}^{3}-\mathrm{x}^{2} \mathrm{~L}\right)
\end{gathered}
$$

To express the axial DOF in (9), the following shape functions are defined:

$$
\mathrm{N}_{1 \mathrm{x}}=1-\frac{\mathrm{x}}{\mathrm{L}} \quad \mathrm{N}_{2 \mathrm{x}}=\frac{\mathrm{x}}{\mathrm{L}}
$$

From the above shape functions, the compatibility vector $\mathbf{B}$, the strain $\varepsilon$, and the stress $\sigma$ can be found via the following expressions:

$$
\varepsilon=\mathrm{Bu} \quad \sigma=\varepsilon \mathrm{E}
$$

More detail about the relationship between compatibility, strain, and displacement in (11) is given by the formula:

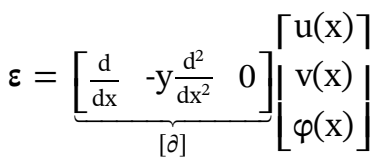

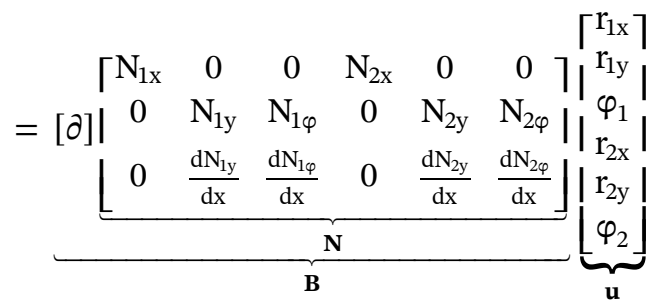

Which result in the following compatibility vector:

$$
\mathbf{B}=\left[\frac{-1}{\mathrm{~L}} \frac{-2 \mathrm{y}}{\mathrm{L}^{3}}(6 \mathrm{x}-3 \mathrm{~L}) \frac{-2 \mathrm{y}}{\mathrm{L}^{3}}(3 \mathrm{x}-2 \mathrm{~L}) \frac{1}{\mathrm{~L}} \frac{-2 \mathrm{y}}{\mathrm{L}^{3}}(-6 \mathrm{x}+3 \mathrm{~L}) \frac{-2 \mathrm{y}}{\mathrm{L}^{3}}\left(3 \mathrm{xL}-\mathrm{L}^{2}\right)^{-}\right.
$$

From (17) and (10) the maximum bending stresses can be found, and in Table 3, it is compared with FEM software results. The determination of such mechanical stresses is an important part of mechanical and civil engineering education.

In this study, all students have been asked to provide results similar to Table 3. For example, this case indicates around 2\% difference in stress levels calculated via ABAQUS and the exercise formula (17)-(19). This can be due to the difference between the result of numerical integration (in ABAQUS) and the exact integration that resulted in formula (3). When the structure is complicated and loading is multiaxial and distributed, derivation of stiffness matrixlike (3) and the force vector (14) are formidable tasks. When software results and calculated results are reasonably close, any student has completed the CT cycle shown in Figure 2 flowchart. Many students completed the cycle by multiple attempts.

\section{6 | METHODOLOGY OF THE RESEARCH}

The methodology of this study is based on a FEM exercise that can strengthen the computational thinking in individual students. Each student has been given an assigned data, and they are allowed to discuss in groups. Moreover, weekly workshop sessions are arranged to guide them via practicing 


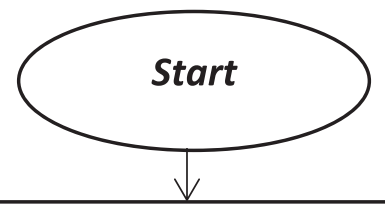

\section{Decomposition}

Designating the number of elements and nodes and DOF's for each node

\section{$\downarrow$ Yes}

\section{Pattern recognition}

i. Seeking $\mathbf{T}_{\mathbf{i}}$ from (1) and $\mathbf{a}_{\mathbf{E i}}$ from (2) for each element.

ii. Designating constrained DOF's $\mathbf{r}_{\mathbf{e}}$ from (11) and unconstrained DOF's $\mathbf{r}_{\mathbf{f}}$ from (12)

iii. The stiffness matrix for each element $\mathbf{K}_{\mathbf{E i}}$ given by (3)-(6).

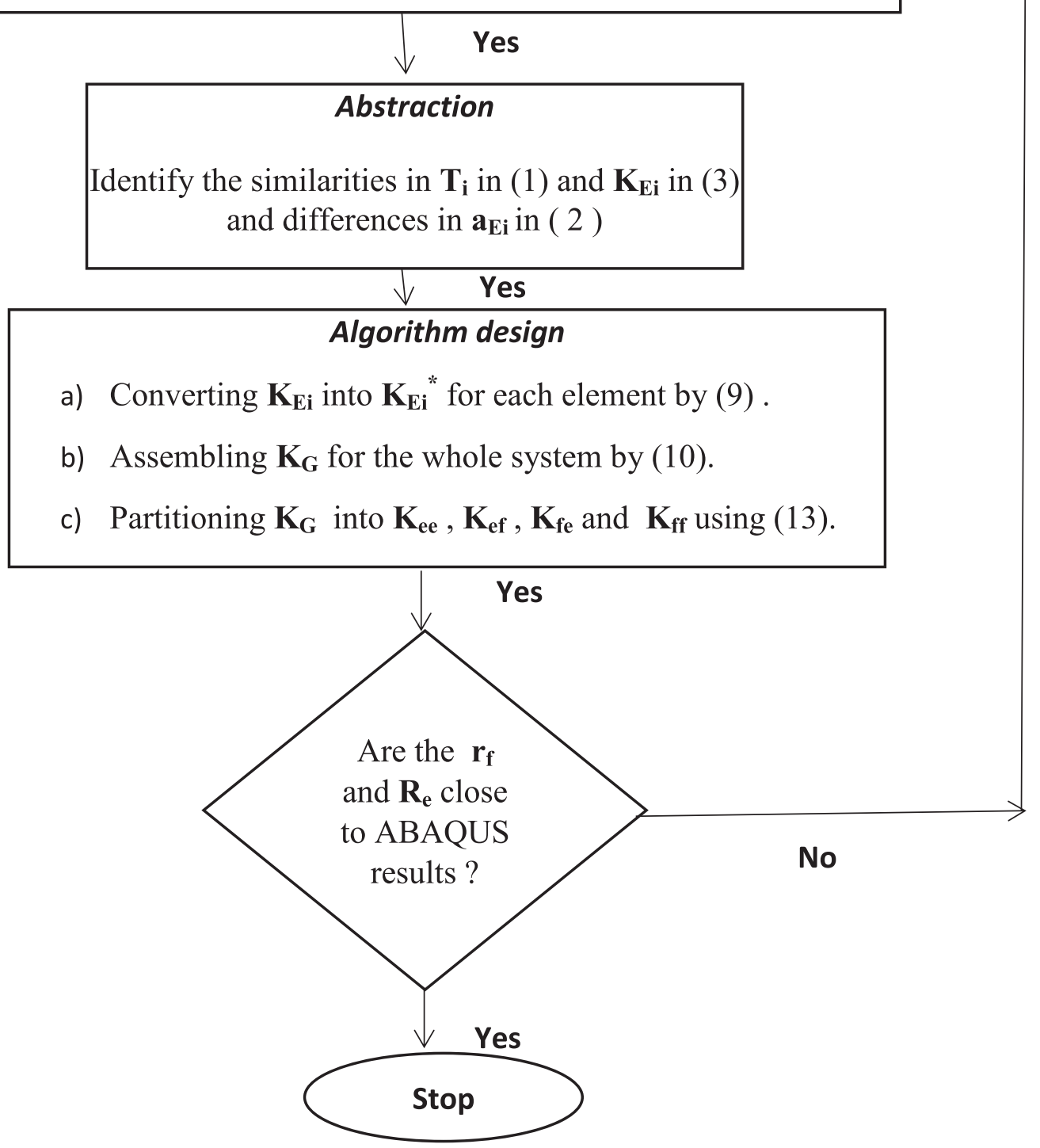


TABLE 1 Allocated lengths

\begin{tabular}{|lll|}
\hline Last name & $\boldsymbol{L}_{\mathbf{1}}(\mathbf{m})$ & $\boldsymbol{L}_{\mathbf{2}}(\mathbf{m})$ \\
& 11 & 9 \\
& 9 & 7 \\
& 12 & 10 \\
& 8 & 6 \\
& 15 & 11 \\
10 & 7 \\
\hline 8 & 6 \\
14 & 10 \\
11 & 6 \\
17 & 13 \\
16 & 12 \\
13 & 11 \\
\hline 12 & 8 \\
\hline
\end{tabular}

a mock assignment. A mixed route has been used such that regardless of group discussions, individual report submission is required. Students are asked about the effectiveness of the scope. All of them confirmed that such an exercise enabled them to understand the details of the computational techniques and compare them with the results of the software. Therefore via such methodology, research goals have been achieved. At the start of the course, the methodology is discussed with students. Based on the feedback received, weekly workshop sessions have been arranged in which many issues, even ethical considerations, have been discussed. The theoretical background is summarised in a flow chart in Figure 2, which thoroughly describes a CT-based stimulation procedure. This will help students to complete the CT cycle much better.
TABLE 2 Comparison of some results

\begin{tabular}{|lll|}
\hline Parameter & $\begin{array}{l}\text { Result obtained via } \\
\text { formulas (1)-(11) }\end{array}$ & $\begin{array}{l}\text { Result obtained via } \\
\text { ABAQUS }\end{array}$ \\
\hline$u_{3}$ & $0.9293 \mathrm{~mm}$ & $0.9257 \mathrm{~mm}$ \\
\hline$\varphi_{3}$ & $-0.265^{\circ}$ degrees & $-0.279^{\circ}$ degrees \\
\hline$R F_{1 x}$ & $-0.69589 \mathrm{MN}$ & $-0.69547 \mathrm{MN}$ \\
\hline$R F_{1 y}$ & $-0.76672 \mathrm{MN}$ & $-0.76008 \mathrm{MN}$ \\
\hline$R M_{1 z}$ & $-0.83196 \mathrm{MN} . \mathrm{m}$ & $-0.78829 \mathrm{MN} . \mathrm{m}$ \\
\hline$R F_{2 x}$ & $-0.30411 \mathrm{MN}$ & $-0.30452 \mathrm{MN}$ \\
\hline$R F_{2 y}$ & $0.54980 \mathrm{MN}$ & $0.54621 \mathrm{MN}$ \\
\hline$R M_{2 z}$ & $-0.33884 \mathrm{MN} . \mathrm{m}$ & $-0.32126 \mathrm{MN} . \mathrm{m}$ \\
\hline$R F_{3 y}$ & $0.21691 \mathrm{MN}$ & $0.21387 \mathrm{MN}$ \\
\hline
\end{tabular}

In total, 20 students participated in this assignment practice. They were in two groups but did the assignment individually according to the data in Table 1. The first group included eight on-campus students who attended the lectures and workshops in person. The second group included 12 online students who watched the recorded workshop sessions and did the assignment. Both groups had performed well and the average mark in each group was very close. This indicates that regardless of the teaching method, the exercise was effective for both groups and produced the desired learning outcomes.

Since the exercise is CT-orientated in nature, all students used four elements of computational thinking in it. In the result section, the snapshots in Figures 4 and 5 indicate some samples for abstraction, decomposition, pattern recognition, and algorithm design.

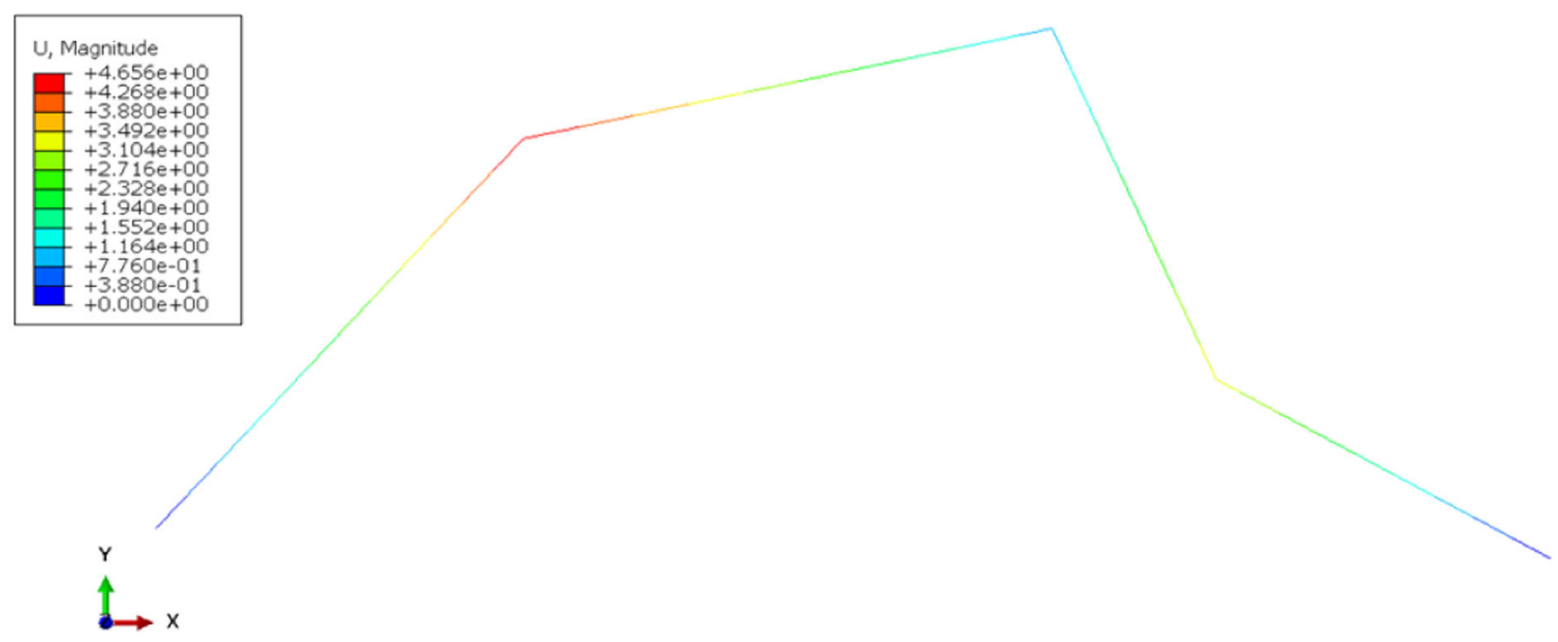

FIG URE 3 Deformed frame with two elements in ABAQUS 
TABLE 3 Comparison of principal stresses

\begin{tabular}{lcc} 
Parameter & Result obtained via formulas (17)-(19) & Result obtained via ABAQUS \\
\hline Maximum $\sigma_{\mathrm{xx}}$ element 1 & $202.1 \mathrm{Mpa}$ & $197.5 \mathrm{Mpa}$ \\
\hline Minimum $\sigma_{\mathrm{xx}}$ element 1 & $-161.8 \mathrm{Mpa}$ & $-157.5 \mathrm{Mpa}$ \\
\hline Maximum $\sigma_{\mathrm{xx}}$ element 2 & $156.9 \mathrm{Mpa}$ & $152.8 \mathrm{Mpa}$ \\
Minimum $\sigma_{\mathrm{xx}}$ element 2 & $-200.8 \mathrm{Mpa}$ & $-196.5 \mathrm{Mpa}$ \\
\hline
\end{tabular}

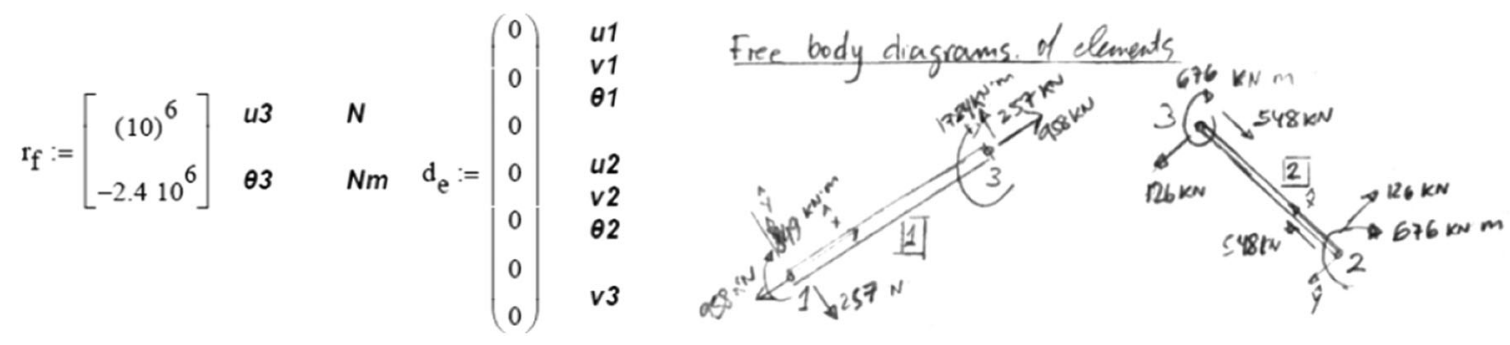

F I G URE 4 sample of the students' work on pattern recognition (left) and decomposition (right)

\section{7 | SAMPLES OF STUDENTS' RESULTS}

All students have followed the steps of computational thinking, as shown in Figure 2. Therefore, they practiced a sophisticated CT exercise. Herein, the snapshots of the students' solution in which the elements of the computational thinking does exist are demonstrated.

From the beginning of the course, the assignment is released to students with the heading shown in Figure 7a. Thereafter, a weekly workshop is arranged in which various steps, as shown in Figure 2, are practiced via a mock assignment. When four workshop sessions are ended, students are given further 4 weeks to do the assignment. In Figure $7 b$, the cover sheet of the submission is shown, indicating that the assignment is not group work but an individual effort.
Figure $7 \mathrm{c}$ shows the sample table of contents, and a typical numerical calculation is shown in Figure $7 \mathrm{~d}$.

Students in this study did an FEM exercise. The explicit form of "pattern recognition" and "decomposition" is shown in Figure 4. Also, Figure 5 shows the explicit form of "abstraction" and "algorithm design." Moreover, the verification by ABAQUS is demonstrated in Figure 6. Therefore, they have done a full CT cycle by completing the assignment.

\section{8 | CONCLUSIONS AND DISCUSSIONS}

There are three main drivers for computing and CT, namely science, technology, and society [20]. Therefore, as demands in society change toward complicated machines and

$$
d_{f}:=K_{f}^{-1} \cdot\left(r_{f}-K_{e f}^{T} \cdot d_{e}\right)=\left(\begin{array}{c}
0.925 \\
-9.024 \times 10^{-5}
\end{array}\right)^{\prime 3}
$$

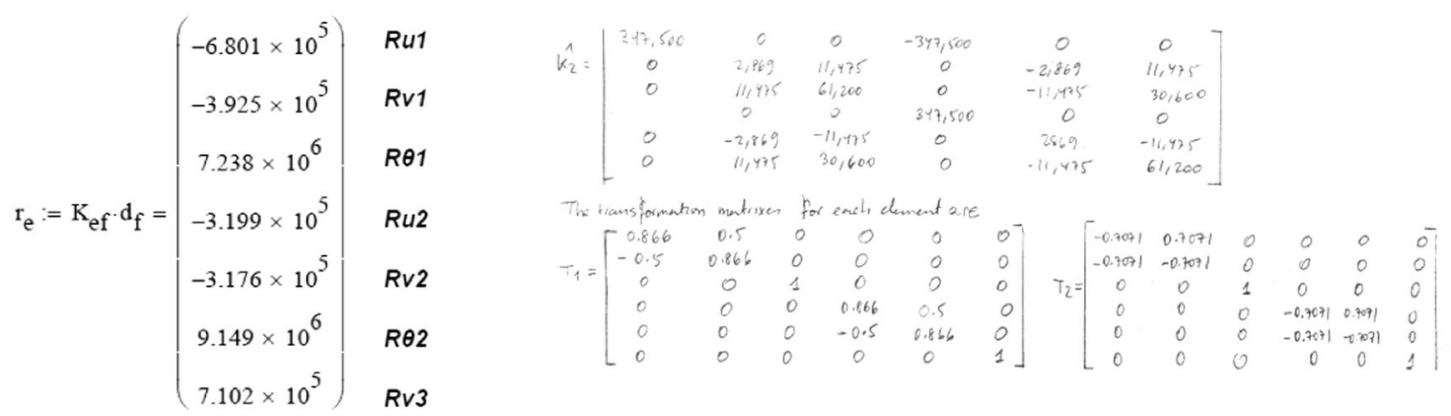

F I G U RE 5 sample of the students' work on abstraction (right) and algorithm design (left) 

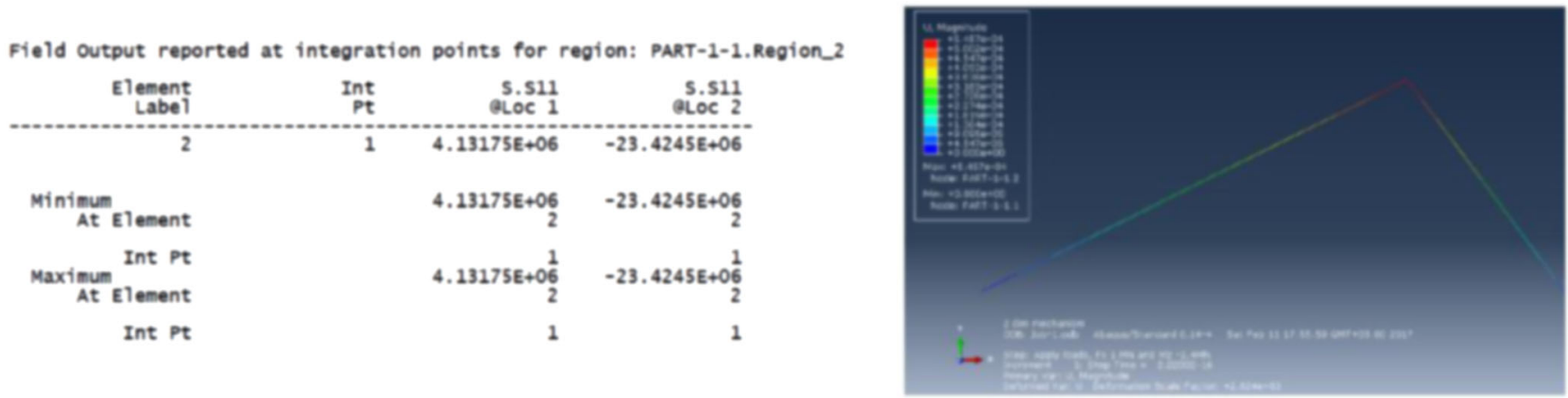

F I G URE 6 sample of the students' work on verification of CT practice in Figure 2 via FEM software ABAQUS

structures, engineering education is faced with new challenges, as witnessed during past decades. To overcome such challenges, the FEM course has been included in postgraduate and also undergraduate studies since the early 1990s [17].

It helped students to analyse the complicated engineering problem, where a substantial amount of computation together with computational thinking was required. Considering FEM courses as a platform to boost the CT skills in engineering students has not been found in the literature. Instead, the existing research mainly focuses on curriculum reform [22]. However, in this study, the FEM course has been described as an excellent platform to improve CT skills at the university level. Therefore this paper fills the gap in this field.

As shown recently in [4], FEM lecturers believe that the content and style in teaching FEM should be reformed. This paper introduces a CT-orientated style of FEM teaching for the first time. Each student solves a simple structure by his/her own CT skills and does the same problem by the inbuilt CT in ABAQUS. Then compares results via Tables 2 and 3. This indicates if (a)

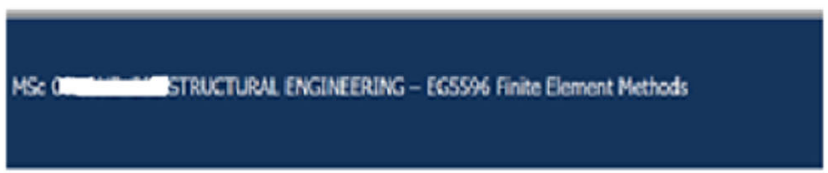

Elastic analysis of a simple frame by hand calculation (b)

\section{SCHOOL OF ENGINEERING}

(d)

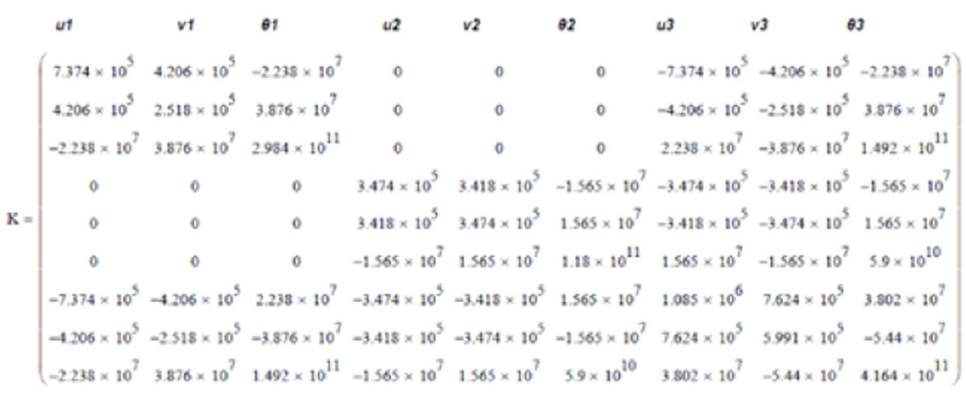

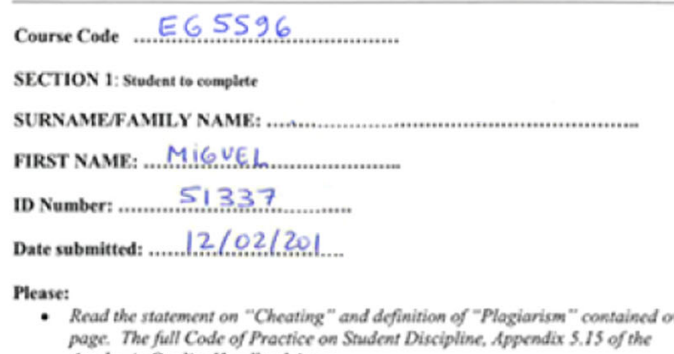

(c)

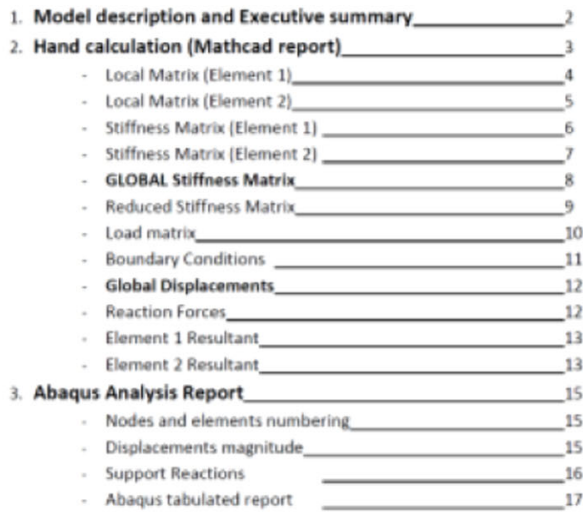

F I G U RE 7 Snapshots showing the features of the assignment. (a) Assignment title, (b) cover sheet of the submitted work by students, (c) table of content of the submitted assignment, and (d) typical numerical calculations 
the cycle of CT practice in the flowchart (Figure 2) is completed or not.

The students are taught formulas (1)-(19) during the course, by which the second column of Tables 2 and 3 is determined. It is shown that how the STEM knowledge combined with CT skills can provide the second column in Tables 2 and 3. When the second column is compared with the third column (created by ABAQUS), it provides a sense of self-efficacy to the students. They will use such software for design and analysis in their future industrial careers. This would help them to handle such software easily.

\section{9 | LIMITATIONS AND RECOMMENDATIONS FOR FUTURE STUDIES}

The present study has been practically implemented in a class with 20 students. This included eight oncampus full-time and 12 online distance-learning students. There are two allocated data columns in Table 1, for two lengths $L_{1}$ and $L_{2}$ (see Figure 1). In mass courses, with a substantial number of students, further data columns can be added to Table 1. This enables more than two parameters plus different boundary conditions to be allocated to each student. The consequence will be further strengthening of their CT skills. Moreover, classes up to 300 students can be accommodated in the course, and the assignment may be assessed digitally. Digital assessment procedure has been described previously in [2].

It can be recommended that such kind of assignment can be used in other fields of engineering education. It should be remembered that the mechanism of data allocation in Table 1 strongly depends on the practical implications. The emphasis here is strengthening CT skills in the individual rather than the group. It is obvious that more complicated assignments can be designed via a similar style to be allocated to groups of students rather than individuals.

Future research can be done to strengthen CT skills in the blended learning environment. Presently, in COVID 19 pandemic situation, a mix of campus studies and online learning are practiced in many universities, and the author is involved in such activities both in undergraduate and postgraduate studies at the University of Aberdeen.

Further research is needed, to extend such CT skills in big group projects where the monitoring procedure of CT aspects is complicated. The author is planning new research to accommodate CTorientated group projects in near future. The structure of such assignments for group work will change substantially.

\section{ACKNOWLEDGEMENT}

The author is grateful to Aberdeen University for encouraging him to do independent research as part of his duties of an academic post.

\section{PEER REVIEW}

The peer review history for this article is available at https://publons.com/publon/10.1002/cae.22440

\section{DATA AVAILABILITY STATEMENT}

The data that support the findings of this study are available from the corresponding author upon reasonable request.

\section{ORCID}

Majid Aleyaasin (DD http://orcid.org/0000-0002-4400-6338

\section{REFERENCES}

1. A. J. Adams, and N. D. P. Barltrop, Dynamics of Fixed Marine Structures, Butterworth-Heinemann Ltd, 1991.

2. M. Aleyaasin, Digital assessment of individual engineering assignments in mass courses, Comput. Appl. Eng. Educ. 26 (2018), no. 5, 1888-1893.

3. K. Beecher, Computational Thinking: A Beginner's Guide to Problem-Solving and Programming, BCS, The Chartered Institute for IT, 2017.

4. Li Cong, Exploration and practice of the curriculum reform of the finite element method, East African Scholars J. Eng. Comput. Sci. 2 (2019), no. 10, 259-261.

5. G. Dasgupta, Finite Element Concepts: A Closed-Form Algebraic Development, Springer, 2018.

6. Dassault Systems, ABAQUS 6.12 documentation, 2012.

7. Z. Deng, W. Huang, R. Dong, and P. Wen, Exploration of ability development of engineering and computational thinking skills in software engineering majors, Proceedings of 4th IEEE International Conference on Computer Science \& Education, pp. 1665-1668, 2009.

8. I. Fronza, N. El Ioini, and L. Corral, Teaching computational thinking using agile software engineering methods: A framework for middle schools, ACM Trans. Comput. Educ. 17 (2017), no. 4, (Art no. 19).

9. S. Gross, M. Kim, J. Schlosser, C. Mohtadi, D. Lluch, and D. Schneider, Fostering computational thinking in engineering education: Challenges, examples, and best practices, IEEE Global Engineering Education Conference (EDUCON), pp. 450-459, 2014.

10. M.S. Hasan Günbatar and H. Bakırcı, STEM teaching intention and computational thinking skills of pre-service teachers, Educ Inform Technol. 24 (2019), 1615-1629.

11. A. Khennane, Introduction to Finite Element Analysis Using MATLAB and ABAQUS, CRC Press, 2013.

12. I. Lee, S. Grover, F. Martin, S. Sarita Pillai, and J. M. Smith, Computational thinking from a disciplinary perspective: integrating computational thinking in K-12 science, technology, 
engineering, and mathematics education, J. Sci. Educ. Technol. 29 (2019), 1-8. https://doi.org/10.1007/s10956-019-09803-w

13. J. Leonard, A. Buss, R. Gamboa, Mitchell Monica, S. F. Olatokunbo, T. Hubert, and S. Almughyirah, Using robotics and game design to enhance children's self-efficacy, STEM attitudes, and computational thinking skills, J. Sci. Educ. Technol. 25 (2016), 860-876.

14. D. L. Logan, A first course in the finite element method, CL Eng. (2010).

15. A. J. Magana and G. S. Coutinho, Modelling and simulation practices for a computational thinking-enabled engineering workforce, Comput. Appl. Eng. Educ. 25 (2017), 62-78.

16. I. T. Monteiro, L. Salgado, M. P. Mota, A. L. Sampaio, and C. S. De Souza, Signifying software engineering to computational thinking learners with AgentSheets and PoliFacets, J. Visual Lang. Comput. 40 (2017), 91-112.

17. S. M. Nesbit, J. Jess Comer, and L. A. Van Gulick, Finite element method in. undergraduate engineering education, Comput. Appl. Eng. Educ. 1 (1993), 299-306.

18. wS. Papadakis, and M. Kalogiannakis, Using gamification for supporting an introductory programming course. The case of classcraft in a secondary education classroom, Interactivity, Game Creation, Design, Learning, and Innovation. ArtsIT 2017, DLI 2017. Lecture Notes of the Institute for Computer Sciences, Social Informatics and Telecommunications Engineering (A. Brooks, E. Brooks, and N. Vidakis, eds.), Vol. 229, Springer, Cham, 2018.

19. S. Papadakis, M. Kalogiannakis, V. Orfanakis, and N. Zaranis, Using Scratch and App Inventor for teaching introductory programming in secondary education. A case study, Int. J. Technol. Enhanced Learn. 8 (2016), no. 3/4, 217-233.

20. J. M. Wing, Computational thinking and thinking about computing, Philosophical Transactions of Royal Society, A 366 (2008), 3717-3725.

21. Y. Yin, R. Hadad, X. Tang, and Q. Lin, Improving and assessing computational thinking in maker activities: the integration with physics and engineering learning, J. Sci. Educ. Technol. 29 (2019), 189-214. https://doi.org/10.1007/s10956-019-09794-8
22. N. Zamani, The Challenges of Teaching Finite Element Analysis in the Undergraduate Curriculum, 14th LACCEI International Multi-Conference for Engineering, Education, and Technology: "Engineering Innovations for Global Sustainability”, San José, Costa Rica. July 20-22, 2016.

\section{AUTHOR BIOGRAPHY}

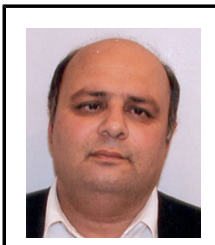

Majid Aleyaasin was born in 1959 and received B.Eng. in 1980 from Mashhad university. He worked in power generation industries up to 1984 and after that received M.Sc. from Sharif University Tehran in 1986. He was lecturer in mechanical engineering in Mashhad university, until 1997. Then he came to Bradford university UK, and received Ph.D. in mechanical engineering in Jan 2001. This followed by working as a research fellow in UMIST and university of Manchester until Dec 2005. Since Jan 2006 he has been researcher and lecturer in school of engineering university of Aberdeen. His research interest lies is in the field of "applied dynamics of solids and structures" and he has taught various subjects in this field both in undergraduate and postgraduate levels.

How to cite this article: M. Aleyaasin, $A n$ Elementary Finite Element Exercise to Stimulate Computational Thinking in Engineering Education, Comput Appl Eng Educ. 2022;30:31-41.

https://doi.org/10.1002/cae.22440 